\title{
Maximization and Control of Nodular Iron Melt's Self-Feeding Characteristics to Minimize Shrinkage
}

\author{
Vitor Anjos ${ }^{1, a^{*}}$, Carlos A. Silva Ribeiro ${ }^{2, b}$ \\ ${ }^{1}$ Centre for Innovation and Technology N.Mahalingam, Rua Dona Maria de Mello Corga, \\ 55 Águeda, Aveiro, Portugal \\ ${ }^{2}$ Universidade do Porto, Faculdade de Engenharia, Rua Dr. Roberto Frias, \\ 4200-465 Porto - Portugal \\ avitor.anjos@citnm.pt, bribeiro@fe.up.pt
}

Keywords: Solidification morphology, nodular cast iron, thermal analysis, pattern yield, selffeeding

\begin{abstract}
This paper describes one possible method to anticipate and control the development of solidification shrinkage, during solidification of nodular cast iron melts, based upon industrial trials made using special designed test castings and closed volume thermal analysis cartridges.

The methodology considers both the solidification morphology and solidification shrinkage critical size, which is always a difficult component of analysis, along with a developed contraction defect index, that allows the application to several types of molten metal and inoculation practices.

The use of thermal analysis allows the recognition of unique melt characteristics, in real time, that are not accessed by more traditional measurement equipment. This allows the definition of thermal analysis patterns that characterize the best melt quality for self-feeding. This is a practical to use and powerful tool for modern foundries, taking advantage of new metric, data collection and data analysis.

Results show that solidification morphology is more accurately determined by thermal analysis, rather than conventional C.E. value, and eutectic solidification morphologies have less need of feeding.
\end{abstract}

\section{Introduction}

Very often is observed that foundries follow strictly the equilibrium phase diagram to predict the solidification morphology of the melt under production, regardless of the fact that the equilibrium diagram was designed under very specific conditions that are not verified in industrial environment, particularly regarding inoculation and undercooling. In general foundries are not aware of the impact that some important process variables, such as inoculation, have in the real solidification morphology.

Taking in account work experiences in foundries around the world and knowing the potentialities of the use of thermal analysis techniques, the objective of this paper is to demonstrate how thermal analysis can be used to define the optimal solidification morphology of a melt to reduce the need of risers and reduce/eliminate some associated contraction defects that arise from the melt's solidification, beyond the prediction of equilibrium phase diagram.

Solidification is characterized by having three contraction stages, represented in Fig.1. From the three contractions stages, solidification contraction is the one with the highest volume variation, followed by liquid contraction and finally solid contraction [1].

However, in the case of cast irons, this contraction is balanced by the expansion of graphite during solidification. Table 1 shows the volume

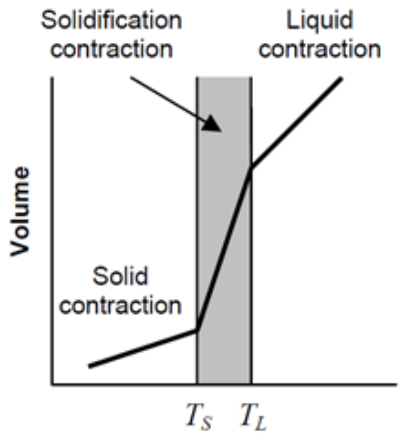

Figure 1 - Volume contraction steps during solidification [1]. density of the distinct phases involved in the stable solidification of cast iron. We can observe that the transformation of Liquid/Austenite will involve a contraction, while Liquid/Graphite will result 
in expansion because graphite has a specific volume that is 3,5 times higher than the specific volume of molten iron.

Table 1 - Density of the different phases involved in the solidification of cast iron [2] [3].

\begin{tabular}{|l|c|}
\hline \multicolumn{1}{|c|}{ Phase } & Specific volume $\left[\mathrm{cm}^{3} / \mathrm{g}\right]$ \\
\hline Liquid cast iron $\left[3,9 \% \mathrm{C}\right.$ at $\left.1450^{\circ} \mathrm{C}\right]$ & 0,143 \\
\hline Austenite $(\mathrm{g}-\mathrm{Fe})\left[20^{\circ} \mathrm{C}\right]$ & 0,136 \\
\hline Graphite $(\mathrm{C})\left[20^{\circ} \mathrm{C}\right]$ & 0,448 \\
\hline
\end{tabular}

Depending on the amount of graphite that solidifies and the time of occurrence of this expansion, the overall solidification contraction can be positive (decrease of volume) or negative (increase of volume). According to Stefanescu [1], ductile iron can have a volumetric solidification contraction variation from $-4,5 \%$ to $2,7 \%$.

In order to compensate liquid and solidification contraction, castings need to have a riser system which supplies additional melt to the one needed to fill the mould cavity, but reduces considerably the pattern yield. Therefore, it is of great interest to maximize the use of graphite expansion to counteract the shrinkage.

Because expansion arises from graphite precipitation, it is critical to control the amount, the distribution and the moment of nucleation and growth of graphite.

Previous works by Hummer et. al. [4] and Gedeonová et. al. [5] using cooling curves and pressure curves from the melt in contact with the mould wall, to reveal that lamellar graphite cast iron has a higher expansion than nodular cast iron for the same eutectic saturation degree ${ }^{1}(\mathrm{Sc})$. According to the study from Gedeonová, hypoeutectic melt compositions of nodular graphite cast iron have higher pressure on the metal/mould interface than hypereutectic melts. Schmidt et al. [6] studied the influence of the eutectic saturation degree on the pressure over the mould wall, showing that for both lamellar graphite and nodular graphite cast iron the pressure increases as the Sc increases from hypoeutectic $(\mathrm{Sc}<1)$ to eutectic $(\mathrm{Sc}=1)$. Unfortunately, in practice the application of these concepts is not easily observed, as there is a crucial difficulty in assuring that the real solidification morphology of the melt follows the one defined by the Sc.

The equilibrium Fe-C diagram does not represent the real solidification morphology (for a given carbon content) for an industrial melt, because cooling rate and other dissolved elements that were not accounted in the equilibrium conditions, affecting the fields and temperatures in the diagram, as schematic presented in Fig. 2 [7]. Therefore, it is very unlikely that in a production process for ductile iron the eutectic reaction occurs for a carbon equivalent predicted by $\mathrm{Fe}-\mathrm{C}$ equilibrium diagram $(4,3 \% \mathrm{C})$.

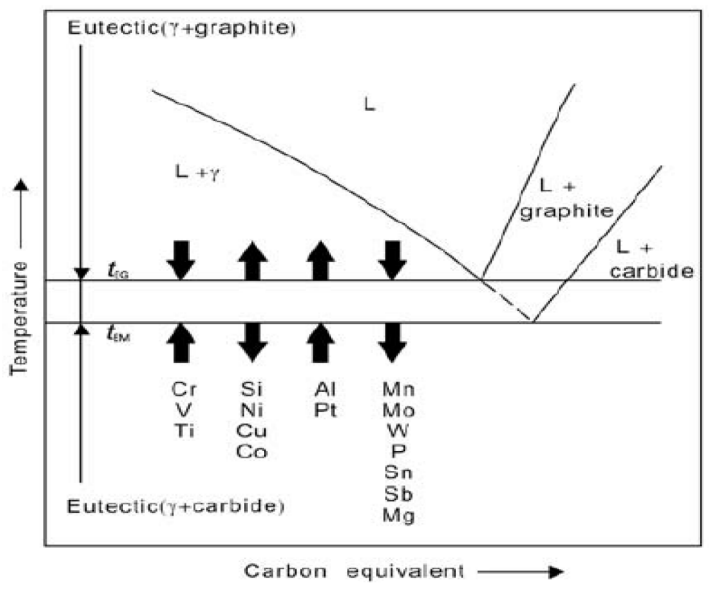

Figure 2 - Effect of alloying elements in the eutectic temperature of the $\mathrm{Fe}-\mathrm{C}$ diagram [7].

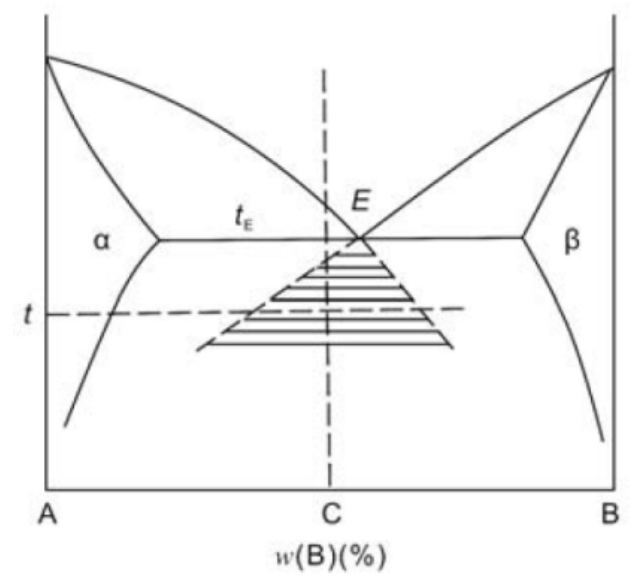

Figure 3 - Illustration of the centralized nonequilibrium eutectic region [7].

\footnotetext{
${ }^{1}$ Eutectic saturation degree $(\mathrm{Sc})-$ Equivalent metallurgical meaning as the C.E. value. Formula: $\mathrm{Sc}=\% \mathrm{C}_{\text {total }} /[4.30-$ 0,3* $(\% \mathrm{Si}+\% \mathrm{P})][4] . \mathrm{Sc}=1$, Eutectic; $\mathrm{Sc}<1$, Hypoeutectic; $\mathrm{Sc}>1$, Hypereutectic.
} 
In order to overcome this limitation in the use of equilibrium phase diagrams, the solidification phase diagram was created, to describe only the relationship in the liquid-solid transition region considering the influence of alloying elements, such as Silicon for example [8].

The thermodynamic solidification conditions of the melt, more specifically the undercooling during solidification, contributes to the non-equilibrium solidification. In case of undercooling at the eutectic temperature, the liquidus line for the austenite liquidus and the graphite liquidus are extended bellow the theoretical eutectic temperature, as suggested in Fig. 3. Between these newly extended liquidus lines, a new region is defined as a non-equilibrium eutectic region also denominated as quasi-eutectic region, where both graphite and austenite can solidify simultaneously for a wide range of carbon content and temperature, and not only the $4,3 \%$ defined in the equilibrium diagram [7].

Additionally, Lesoult et.al. demonstrated that segregation of carbon during solidification will cause variations on the predictable solidification morphology of a melt, especially in hypereutectic compositions [9].

In foundry practice, it is not necessary to create complex solidification diagrams for every melt compositions and still have difficulties for predicting the influence that undercooling has on the solidification morphology. The easiest way to determine the real solidifications morphology is using advanced thermal analysis for the stable solidification of a melt sample. Extensive work from Baumgart et.al. [10] using thermal analysis curves obtained from closed thermal analysis cups (Ther-O-Stack ${ }^{\circledR}$ from Heraeus Elektro-Nite), and later proven experimentally by Anjos [11], suggested a pattern to recognize the solidification morphology of a melt for ductile iron thermal analysis curves, presented in Fig. 4. Hypoeutectic curves are characterized, in the liquid to solid transformation, by having two main inflection points in the solidification phase (corresponding to liquidus and eutectic temperatures respectively), where the first inflection has a much smaller recalescence compared to the second inflection. Eutectic solidification curves are characterized, in the liquid to solid transformation, by having only one inflection and hypereutectic curves have again two inflections (corresponding to liquidus and eutectic temperatures) but the first inflection has a greater recalescence than the second one.

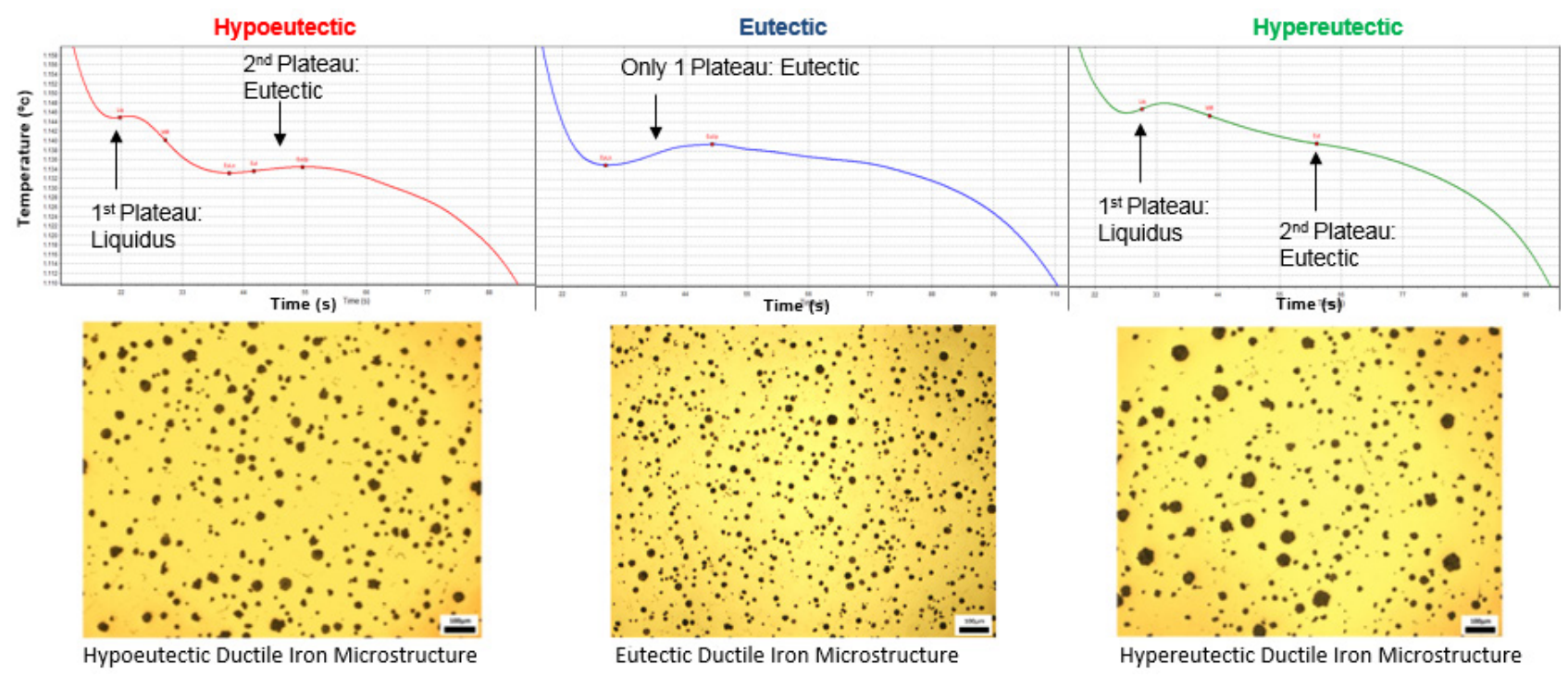

Figure 4 - Display of the liquid/solid transformation of solidification curves from 3 melts with changing C content. C.E. values: hypoeutectic C.E. $=4,37 \%$; Eutectic C.E. $=4,47 \%$; Hypereutectic C.E. $=4,58 \%$ [11].

Previous work developed by Anjos et.al. [11,12], demonstrated that depending on the carbon content and specially the undercooling (inoculation potential) of the melt, it is possible to have a hypoeutectic solidification for C.E. values well above $4,3 \%$, as presented in Fig. 5, showing deviation of real solidification conditions from those predicted after $\mathrm{Fe}-\mathrm{C}$ equilibrium diagram. From the figure, it is possible to see that the solidification curves are hypoeutectic, for C.E. above $4,45 \%$ and eutectic temperature is at around $1138{ }^{\circ} \mathrm{C}$. The determination of the solidification 
morphology should always be done using thermal analysis evaluation of the melt after treatment and prior to pouring.

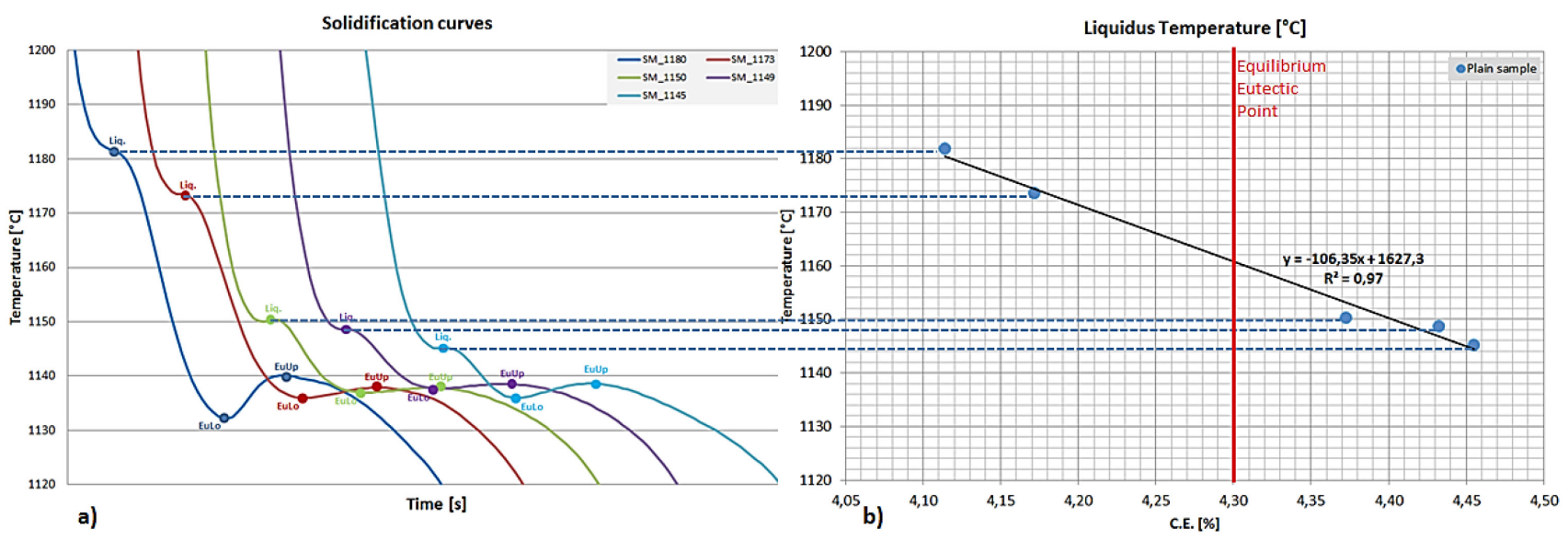

Figure 5 - a) Section of solidification curves in the liquid/solid transformation, from same base iron with different carbon contents; b) relation between the liquidus temperature from the solidification curve and the C.E. value.

Knowledge of the real solidification morphology, of a ductile iron melt, is crucial to better adjust process variables and obtain a solidification of the melt in the mould cavity capable of using the maximum expansion of graphite and lower need of risers. The determination of the best thermal analysis curve pattern to achieve this minimal need of raiser, was the main objective of the experimental work presented here after.

\section{Experiment}

The following experiment was conducted in a foundry under production conditions for regular GJS400 iron. Main objective was to study the influence of the melt solidification morphology on the feeding requirements of the melt. The solidification morphology type was determined through the use of thermal analysis.

For the characterization of the volume defects, the classifications proposed by Stefanescu [1] and Hasse [2] were followed, helping to define the general classification used in this work and presented in Fig. 6. To allows a global evaluation of the contraction defects in the casting, regardless of the defect denomination or origin, a Contraction Defect Index is calculated (Eq. 1). The calculation of this Index is done by multiplying the area of the defects (resulting from a cut of the test casting through its thermic centre) by the defect intensity, defined in Figure 6 (porosity defects have a lower contraction index and open shrinkage have a higher index).

The use of the contraction index helps to overcome the common difficulty of characterizing a defect that has a
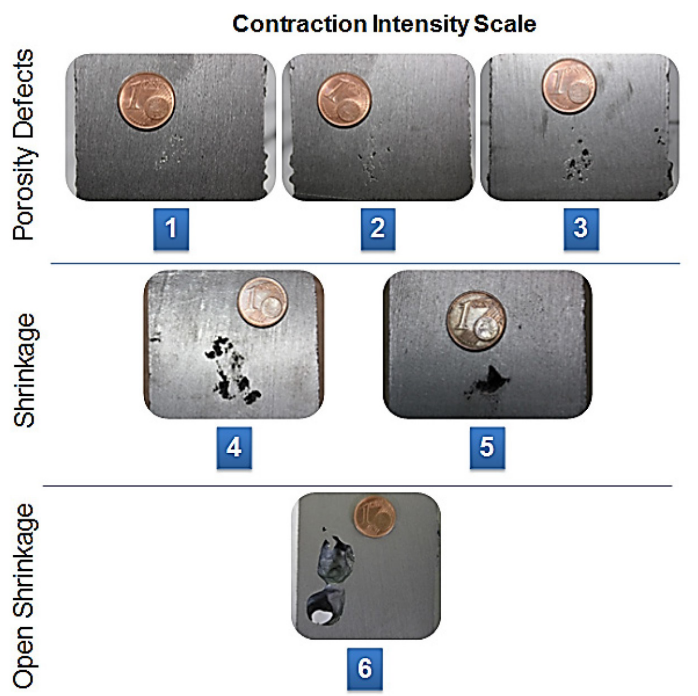

Figure 6 - Defect classification and contraction intensity scale. 3D shape only by observing a 2-dimensional cut from that defect.

\section{Contraction Defect Index $=$ Defect Area $\left(\mathrm{mm}^{2}\right)$ x Defect Intensity Index.}

For trials, a test casting was developed to allow the determination of the contraction defects magnitude from a given melt, as shown in Fig. 7. The gating system was connected to section 1 of the test casting and the defect evaluation was done in section 3. From each poured mould, two test 
castings were evaluated and the average contraction defect from both test castings was calculated. The moulds were produced using resin bonded sand.
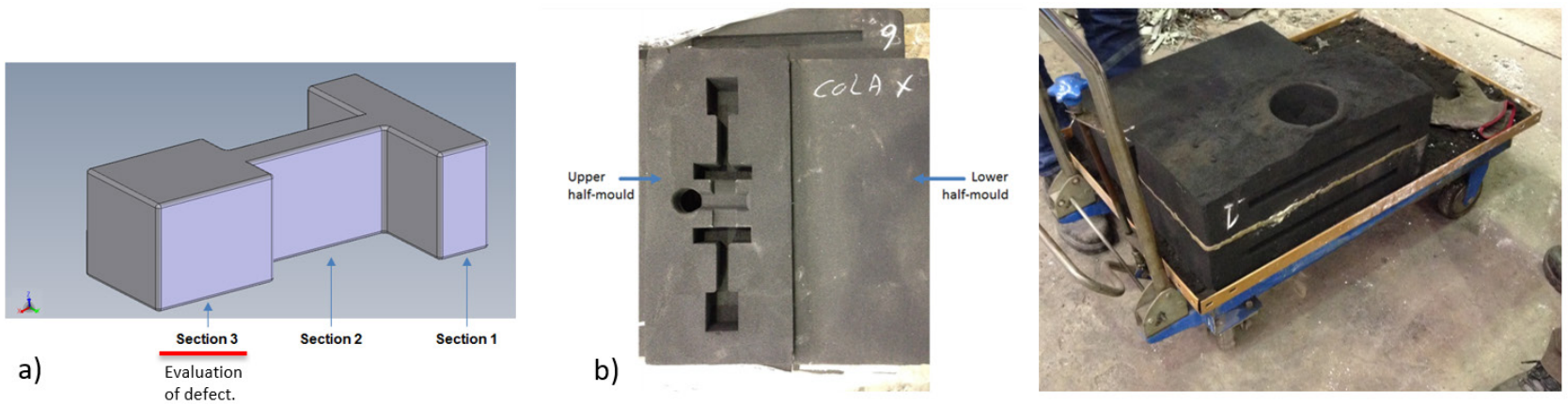

Figure 7 - a) Model developed to evaluate contraction defects; b) Sand mould used for trials.

The trial was executed during regular production in a foundry that uses middle frequency crucible electrical furnaces to melt, Sandwich method for treatment and pouring is performed directly from the treatment ladle into the moulds. Tests from three different base iron melts were made in order to achieve the desirable distribution of melt solidification morphologies. The melt used was GJS400, using a charge composed by low Mn steel scrap, returns, $\mathrm{SiC}, \mathrm{FeSi}$ and graphite. The chemical compositions of the melts used are as shown in Table 2.

Table 2 - Chemical composition from the base iron melts used on the trials.

\begin{tabular}{ccccccccccc}
\hline $\begin{array}{c}\text { Base } \\
\text { iron nr. }\end{array}$ & $\begin{array}{c}\mathbf{C} \\
{[\mathbf{\%}]}\end{array}$ & $\begin{array}{c}\mathbf{S i} \\
{[\mathbf{\%}]}\end{array}$ & $\begin{array}{c}\mathbf{M n} \\
{[\mathbf{\%}]}\end{array}$ & $\begin{array}{c}\mathbf{P} \\
{[\mathbf{\%}]}\end{array}$ & $\begin{array}{c}\mathbf{S} \\
{[\mathbf{\%}]}\end{array}$ & $\begin{array}{c}\mathbf{C u} \\
{[\mathbf{\%}]}\end{array}$ & $\begin{array}{c}\mathbf{S n} \\
{[\mathbf{\%}]}\end{array}$ & $\begin{array}{c}\mathbf{N i} \\
{[\mathbf{\%}]}\end{array}$ & $\begin{array}{c}\mathbf{C r} \\
{[\mathbf{\%}]}\end{array}$ & $\begin{array}{c}\mathbf{P b} \\
{[\mathbf{\%}]}\end{array}$ \\
\hline 1 & $\mathbf{3 , 8 0}$ & 1,82 & 0,41 & 0,013 & 0,005 & 0,026 & 0,011 & 0,063 & 0,032 & 0,002 \\
2 & $\mathbf{3 , 8 4}$ & 1,76 & 0,40 & 0,015 & 0,006 & 0,022 & 0,009 & 0,063 & 0,037 & 0,002 \\
3 & $\mathbf{3 , 9 4}$ & 2,07 & 0,42 & 0,012 & 0,006 & 0,036 & 0,012 & 0,065 & 0,031 & 0,002 \\
\hline
\end{tabular}

The Sandwich treatment was performed using a FeSiMg alloy $(44,6 \% \mathrm{Si} ; 1,19 \% \mathrm{Ca} ; 6,2 \% \mathrm{Mg}$; $0,64 \% \mathrm{Al}$ and $0,64 \% \mathrm{RE})$ and Inoculant $(66,9 \% \mathrm{Si} ; 1,81 \% \mathrm{Ca} ; 1,69 \% \mathrm{Ba} ; 1,06 \% \mathrm{Al} ; 2,45 \% \mathrm{Zr}$ and $2,74 \% \mathrm{Mn})$. A total of 9 ladles were treated and poured. The process data regarding the treatment of each ladle and pouring temperature are given in Table 3. After treatment of each ladle, a thermal analysis sample and spectrometer sample was taken from the melt. The thermal analysis system used was the one from Heraeus Electro Nite (PhaseLab Software and Therm-O-Stack ${ }^{\circledR}$ closed cup). The results from the spectrometer samples are presented in Table 4.

Table 3 - Treatment and pouring process data from trials.

\begin{tabular}{c|cccccc}
$\begin{array}{c}\text { Ladle } \\
\text { No. }\end{array}$ & $\begin{array}{c}\text { Base } \\
\text { iron } \\
\text { No. }\end{array}$ & $\begin{array}{c}\text { Treat. } \\
\text { Weight } \\
{[\mathrm{Kg}]}\end{array}$ & $\begin{array}{c}\text { Tap Temp. } \\
{\left[{ }^{\circ} \mathrm{C}\right]}\end{array}$ & $\begin{array}{c}\text { Nodularizer } \\
(\% \text { of treat. weight })\end{array}$ & $\begin{array}{c}\text { Inoculant } \\
(\% \text { of treat. weight })\end{array}$ & $\begin{array}{c}\text { Pouring } \\
\text { Temp. } \\
{\left[{ }^{\circ} \mathrm{C}\right]}\end{array}$ \\
\hline DC_1 & 1 & 1162 & 1439 & 1,29 & 0,46 & 1364 \\
DC_2 & 1 & 1080 & 1438 & 1,39 & 0,49 & 1380 \\
DC_3 & 1 & 1040 & 1451 & 1,54 & 0,46 & 1377 \\
DC_4 & 1 & 1000 & 1450 & 1,50 & 0,53 & 1370 \\
DC_5 & 2 & 1100 & 1437 & 1,45 & 0,38 & 1380 \\
DC_6 & 2 & 986 & 1438 & 1,52 & 0,54 & 1369 \\
DC_7 & 3 & 1036 & 1437 & 1,45 & 0,41 & 1382 \\
DC_8 & 3 & 1046 & 1435 & 1,43 & 0,40 & 1364 \\
DC_9 & 3 & 1000 & 1437 & 1,5 & 0,42 & 1378
\end{tabular}


The thermal analysis curves are presented in Fig. 8, where they are ordered according to their solidification morphology, from the less hypoeutectic to the more hypereutectic.

Table 4 - Chemical composition from the melt at pouring.

\begin{tabular}{c|ccc|}
$\begin{array}{c}\text { Ladle } \\
\text { No. }\end{array}$ & $\begin{array}{c}\text { C } \\
{[\text { \%] }}\end{array}$ & $\begin{array}{c}\text { Si } \\
{[\text { \%] }}\end{array}$ & $\begin{array}{c}\text { Mg } \\
\text { [\%] }\end{array}$ \\
\hline DC_1 & 3,60 & 2,63 & 0,040 \\
DC_2 & 3,56 & 2,7 & 0,043 \\
DC_3 & 3,63 & 2,67 & 0,047 \\
DC_4 & 3,54 & 2,68 & 0,046 \\
DC_5 & 3,68 & 2,59 & 0,047 \\
DC_6 & 3,70 & 2,54 & 0,043 \\
DC_7 & 3,65 & 2,88 & 0,048 \\
DC_8 & 3,56 & 2,89 & 0,053 \\
DC_9 & 3,6 & 2,87 & 0,050
\end{tabular}

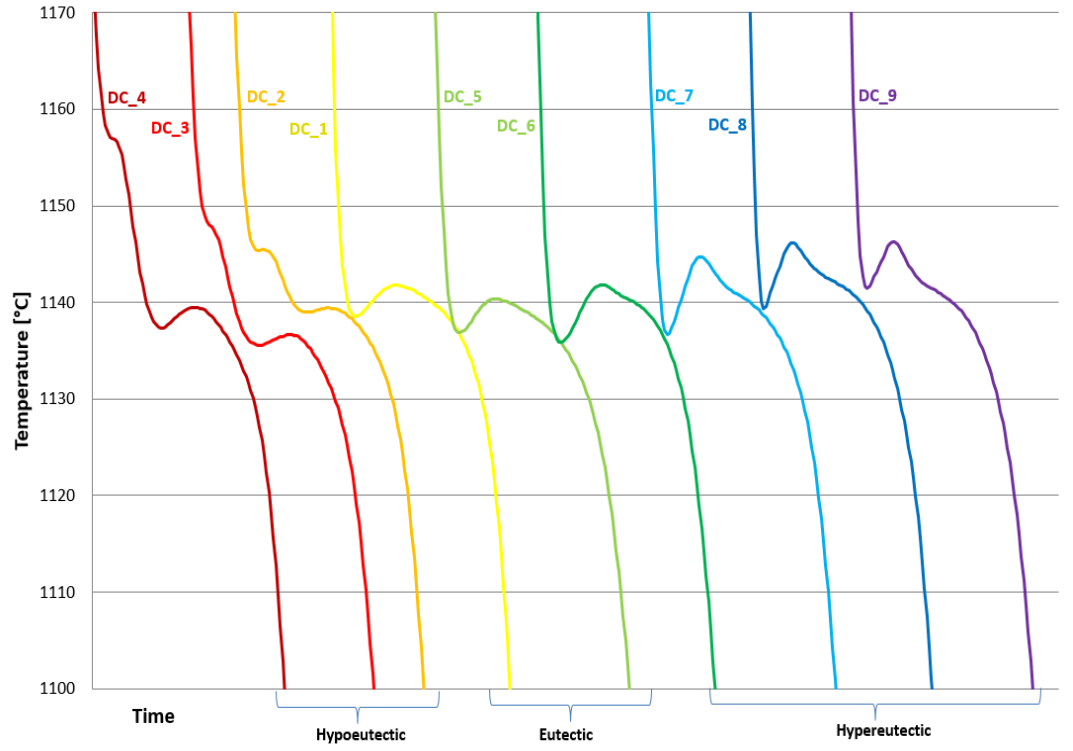

Figure 8 - Thermal analysis curve section on the solid/liquid transformation, showing the different solidification morphologies of the melt.

From Fig. 8, it is observed that all 3 possible solidification morphologies were obtained from trials, from highly hypoeutectic (DC4) to eutectic (DC1 and DC5) to highly hypereutectic (DC9). From the poured moulds, the castings where cut though the thermic centre of section 3 , and the observed defects were measured and classified according to the contraction intensity scale from Fig. 6 . Then, using the equation 1, the contraction defect index was calculated and the results are presented in Fig. 9.

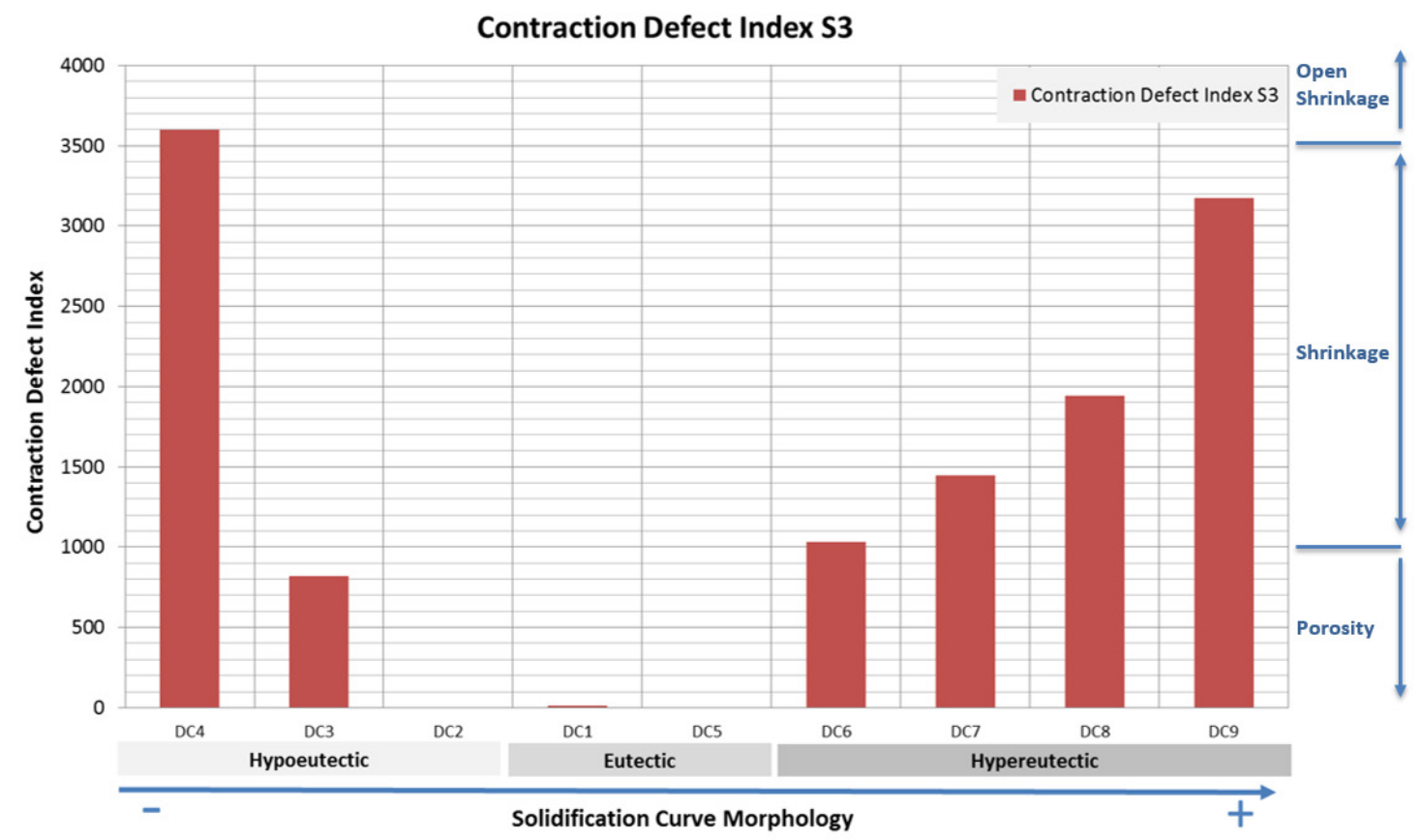

Figure 9 - Contraction defect index results for different melt solidification morphologies.

Results from the casting inspection, reveal that the solidification morphology that has the best selffeeding characteristics is the eutectic and close to eutectic morphologies. The lowest defect volume was found for melts DC1 and DC5 that have eutectic morphology and for the DC2 that has a hypoeutectic morphology very close to eutectic. 
Highly hypereutectic melts, like DC4, showed the biggest contraction defect (open shrinkage). Hypoeutectic and hypereutectic melts, like DC3 and DC6 respectively, that are close to the eutectic solidification point, showed small porosity defects.

As the melt composition gets more hypoeutectic, and gets away from the eutectic point, the contraction defect grows from porosity to shrinkage (closed shrinkage) and gets bigger as the melt solidifies more hypereutectic.

If we attempt to reproduce the presentation of results for the contraction defect index, and order the different experimental data by order of the calculated carbon equivalent (C.E. $=\mathrm{C}+$ $(\mathrm{Si}+\mathrm{P}) / 3)$, we obtain the result presented in Fig. 10. We can see that it is not possible to find a clear tendency of contraction defects depending on C.E. value. This exercise proves that thermal analysis is more accurate in relating solidification morphology with the contraction defects in castings.

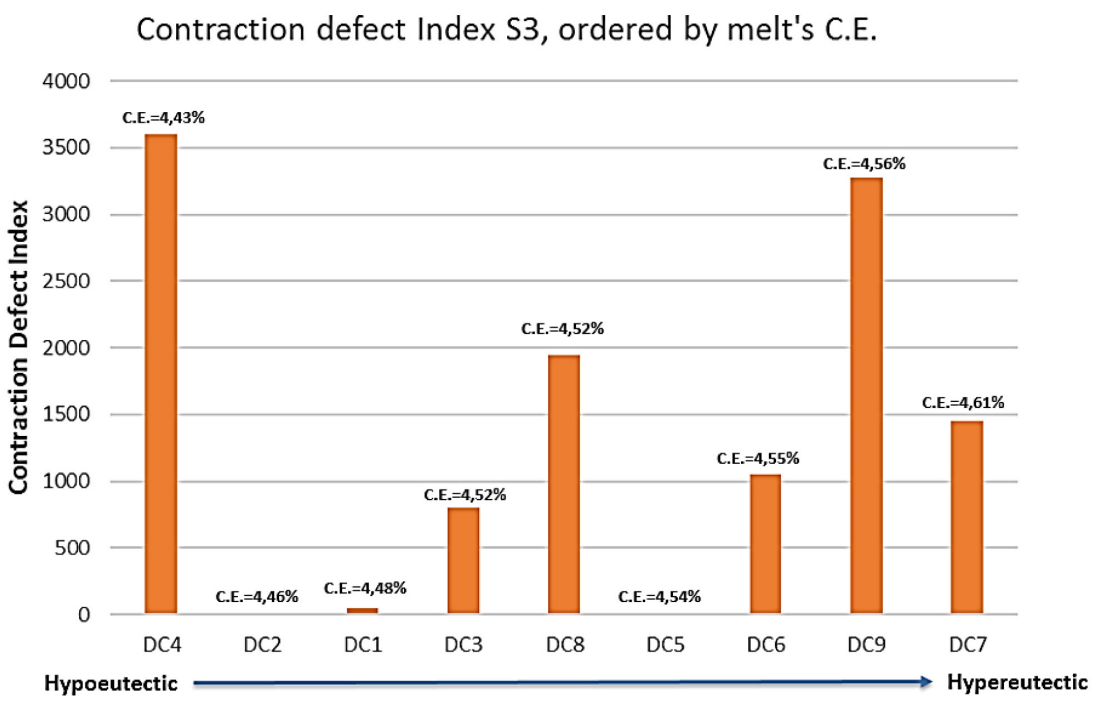

Figure 10 - Contraction defect index ordered by C.E. value.

\section{Conclusions}

From the literature review and experiments presented in this paper, it is established that the common assumption of using the calculated Carbon Equivalent to forecast the solidification morphology of the melt is inaccurate, especially in near eutectic melt composition, like those used in the production of nodular cast iron melts.

Thermal analysis seems far more reliable to suggest real solidification morphology and allows therefore a better correlation with solidification defects such as shrinkage and porosity.

From this work, it is also demonstrated that melts that have an exact or near to eutectic solidification morphology (determined by thermal analysis) are the ones with less solid to liquid contraction defects, and therefore the ones that will require less need of risers and will give better pattern yield.

\section{References}

[1] D. M. Stefanescu, Science and Engineering of Casting Solidification, Springer Science+Business Media, New York, 2009, pp. 1-4

[2] S. Hasse, Guß- und Gefügefehler, Schiele \& Schön GmbH, Berlin, 2003.

[3] I. Jimbo and A. W. Cramb, The density of liquid iron-carbon alloys, submitted to Metall. Mater. Trans. A, 24 (1993), pp. 5-10.

[4] R. Hummer, Beurteilung der Lunkerneigung von Gußeisen mit Kugelgraphit mittels Abkühl- und Längeänderungskurven, submitted to Giesserei-Praxis Nr.9/10, pp. 142-151, (1989)

[5] Z. Gedeonová, J. Dúl and S. Bódi, Die Bewegung der Grenzfläche Metall/Form Wärend der Erstarrung von Gußeisen mit Kugelgraphit und Lamellengraphit, submitted to Gießerei-Praxis Nr. 7/8, pp. 150-155, (1996)

[6] W. Schmitz and S. Engler, Ausdehnungsdrücke während der Erstarrung von Gußeisen mit Lamellen- und Kugelgraphit, submitted to Giesserei 77 (11) (1990), 372-375.

[7] J. Zhou, Colour Metallography of Cast Iron - Chapter 1 Introduction (I), submitted to China Foundry, vol. 6, pp. 57-65, (2009) 
[8] W. R. Heine, The Fe-C-Si Solidification Diagram for Cast Iron, AFS Transactions, 1986, 391-403

[9] G. Lesoult, M. Castro and J. Lacaze, Solidification of Spheroidal Graphite Cast Irons - I Physical Modelling, submitted to Acta Metall., 46 (3) (1998), 983-995.

[10] W. Baumgart, Untersuchung des Phasenübergangs von flüssig nach fest am tertiären System Fe-C-Si unter Nichtgleichgewichtsbedingungen, submitted to Lehrstuhl für das gesamte Gießereiwesen und Gießerei-Institut der RWTH Aachen, Aachen, (2013)

[11] V. Anjos, Use of Thermal Analysis to Control the Solidification Morphology of Nodular Cast Irons and Reduce Feeding Needs" Submitted for PhD thesis at Universität Duisburg-Essen, Duisburg, (2015)

[12] V. Anjos, C. S. Ribeiro, J. Cunha and C. Gomes, The use of thermal analysis to compare solidification pattern, and evaluate performance, of several inoculants, in ductile iron., submitted in 71st World Foundry Congress, Bilbao, (2014) 